\title{
Quality as a Function of Quantity in Electronic Brainstorming
}

\author{
Robert O. Briggs \\ Center for the Mgt. of Info. \\ University of Arizona \\ bbriggs@bpa.arizona.edu
}

\author{
Bruce A. Reinig \\ Information Systems Dept. \\ Hong Kong University of \\ Science and Technology \\ reinig@bpa.arizona.edu
}

\author{
Morgan M. Shepherd \\ Information Systems Dept. \\ University of Colorado, \\ Colorado Springs \\ mmshepherd@uccs.edu
}

\author{
Jerome Yen \\ Computer Science Department \\ Hong Kong University \\ Jyen@cs.hku.hk
}

\author{
Jay F. Nunameker, Jr. \\ Center for the Management of Information \\ University of Arizona \\ nunamaker@bpa.arizona.edu
}

\begin{abstract}
The quality of ideas a team generates constitutes an upper limit on the quality of the problem solving process. Much research has been done about causes of idea quantity and causes of idea quality. It has been noted by some researchers that idea quality appears to correlate with idea quantity, and several have argued that it is not necessary to go to expense and effort required to evaluate idea quality since it correlates with quantity. This paper draws on Team Theory to develop a causal link between quantity and quality. It then presents a low-cognitive-load, high-reliability method for evaluating idea quality. It reports on $a$ study that addresses the question, "Will an increase in idea quantity cause more good ideas to be generated?" The results support the hypothesis that there is a modest causal connection between quantity and quality, but the data suggest other factors are far more important for determining the number of good ideas a team generates. It concludes that researchers must continue to measure the effects of their brainstorming treatments on idea quality; it is not sufficient to assume that quality will always track quantity. Other factors not accounted for by the quality-quantity model may well counter and outweigh this effect.
\end{abstract}

\section{Introduction}

Idea generation is an important part of all phases of problem solving (Andriole, 1983; Brightman, 1980; Bross, 1953, Dunker, 1945). The quality of ideas generated constitutes an upper limit on the quality of the problem-solving process. Many problems are so large that no one person has all the experience, insight, or resources to solve the problem alone. In such cases people must make a joint effort to achieve their goal. A key part of that effort is group idea generation.
A great deal of research has been completed to create and improve methods for group idea generation. (See Diehl \& Stroebe, 1987; Dennis \& Gallupe, 1993; Fjermestad, Hiltz, \& Turoff, 1993 for reviews). Since Osborn first introduced brainstorming it has asserted (or hoped) that groups who produce more ideas would also produce better ideas (Osborn, 1953). Much of brainstorming research focuses on methods to produce more ideas. Several studies have reported idea quality as well, and a few key papers report that idea quality does indeed correlate with idea quantity (Diehl \& Stroebe, 1987; Dennis, Valacich, \& Nunamaker, 1990; Gallupe, et al., 1992; Valacich, Wachter, Mennecke, \& Wheeler, 1993).

Evaluating idea quality can be a grueling, expensive, and uncertain task. Some studies do not address idea quality (Paulus \& Dzindolet, 1993; Gopal, Bostrom, \& Chin, 1993; Shepherd, Briggs, Reinig, Yen, \& Nunamaker, 1995-96; ), while others argue that the existing empirical evidence precludes the necessity for going to the expense and effort of measuring idea quality.

The empirical record is equivocal, however. Some studies did not find a correlation between quality and quantity (For example, Connolly, Jessup, \& Valacich, 1990). Because idea quality limits problem-solving quality, it is important to understand the genesis of idea quality, what causes high quality, and what causes poor quality. A theoretical model of idea quality could lead to rigorous investigation of whether and when quality follows quantity, which in turn could free researchers to pursue quantity secure in the knowledge that quality will follow. Such a foundation might also let practitioners reason about when quality will not follow quantity, and avoid bad meeting practices. Toward these ends, it might also be useful for researchers to find a fast, inexpensive, and reliable way to measure quality, to make investigations more feasible.

This paper offers a theoretical argument about why idea quantity should cause higher idea quality. It then describes a 
low-cognitive-load, high-reliability method for evaluating idea quality. The paper presents the findings of an empirical investigation into the relationship between idea quantity and quality, and finishes with a discussion on the implications of the results for researchers and practitioners.

\section{Team Theory}

Is it reasonable to think that generating more ideas should cause higher-quality ideas? Team Theory (Briggs, 1994, Briggs, \& Nunamaker, 1996) offers a basis for arguing that it should. It is beyond the scope of this paper to fully examine the details of Team Theory, but an overview, may be a useful foundation upon which to build the argument.

Team Theory offers a causal model for the productivity of a group of people making a joint cognitive effort toward a goal. It defines a group as the collection of people who have agreed to expend effort to achieve a goal. It defines productivity as the degree to which the group achieves its stated goal. Team theory conceives productivity having two key components: efficiency effectiveness (Prichard, Jones, \& Roth, 1990). Efficiency refers to the degree to which resources are conserved during the accomplishment of a goal, while effectiveness refers to the quality of the outcome achieved.

Team theory posits that limits on human attention resources are key constraints on group productivity. Some authors discuss attention in terms of cognitive load or cognitive effort (Gilbert \& Osborne, 1989). However, it is important to recognize that attention has a temporal component. People do not exert massive cognitive effort in instantaneous bursts. Attention is therefore defined as cognitive effort over time. This temporal component is a critical element for understanding group processes (McGrath, 1991).

\footnotetext{
${ }^{1}$ Team Theory originally appeared under the name, "Focus Theory.
}

Team Theory posits that in order to achieve the group goal, members must allocate their attention among at least three processes: communication, deliberation, (DeSanctis \& Gallupe, 1987) and information access (Figure 1). Each of these processes places demands on limited attention resources, and therefore interferes with the other with the other processes (Brainerd \& Reina, 1990). Team Theory further posits that cognitive effort is motivated by vested interest. Therefore, it posits that group productivity will be a function of goal congruence, or the degree to which the public goal of the group is compatible with the private interests of the group members.

Communication, as conceived in Team Theory, is a multilateral process (Hatch, 1977; Poole \& Jackson, 1993; Shannon \& Weaver, 1964) involving the creation of stimuli words, images, behaviors, objects (Burgoon, 1985) - in some media (Daft \& Lengel, 1984) - paper, voice, video, etc. The targets of communication perceive and assign meanings stimuli

(Daft \& Weick, 1984; Kosslyn, 1981; Short, Williams, \& Christie, 1976) and create more stimuli which are perceived by the initiator, who may, in turn, modify outgoing communication in response. For instance, puzzled looks from a listener often prompt a rephrasing from a speaker.

Team Theory frames the Information Access process as an economic trade-off of the benefits derived from information and the attention required to access it. It posits that the function of information to increase the probability that one will expect the outcome one derives by selecting one course of action over others. Information has value to the extent that it is timely, accurate, and complete, and this value is offset by the cognitive costs for finding, , assimilating, retrieving, and using the information.

Team theory frames deliberation as the cognitive processes required to form and execute intentions with respect to the group goal. The concept of intentions is broader and more inclusive than the concept of goals. A goal is a desired end state, but an intention includes the goal and a notion of the actions required to achieve the goal, the duration and intensity of action, resources required, etc. (Ajzen, 1985; Campbell \& Prichard, 1976; Kuhl, 1985; Tubbs \& Ekeberg, 1991). 
There is a generic and seemingly ubiquitous set of deliberative processes associated with goal attainment. Many disciplines formalize their deliberative processes into structured methods. While the methods of these many disciplines differ, there are striking similarities in the processes upon which they are founded. Team Theory describes a generic deliberative process:

1. Understand the existing and desired situations

2. Generate alternative courses of action

3. Evaluate possible outcomes of alternatives

4. Select courses of action

5. Plan the execution

6. Execute

7. Monitor results

The list above may appear to be an orderly step-by-step process, but the theory does not frame it as such. People may engage in these activities randomly, starting anywhere, working

\section{Team Theory and Idea Quality}

Team Theory offers a host of explanations for the quantity of ideas a group might produce. Assuming equal ability and equal distraction across teams, difference in communication channels may induce varying degrees of attention blocking, airtime fragmentation, and other forms of production blocking (Diehl \& Stroebe, 1987); there may be differences in the cognitive costs of information access; deliberative processes may have a greater or lesser degree of order; teams may have a range of vested interests in achieving the outcomes.

The effects of many of the commonly used variables used in brainstorming research may be explained by the four constructs of Team Theory. For example, people suffering evaluation apprehension, a goal congruence issue, may produce fewer ideas. Social comparison, another goal congruence issue, may also affect the effort expended by a team producing ideas

Figure 2.

Mechanisms Whereby Idea Quantity Causes Idea Quality During Group Problem-Solving Activities

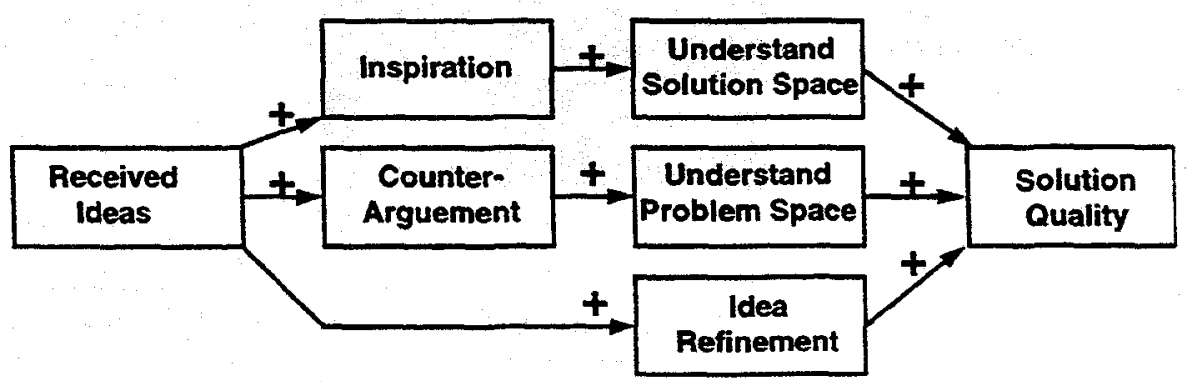

activities singly or in parallel, and jumping to any other activity.

Team Theory conceives of goal congruence as a motivation for the cognitive effort required to achieve a goal. To the extent that an individual perceives that the team goal is at least compatible with individual goals, the participant will expend effort to achieve the goal. A given team member may have numerous personal goals, and these goals may even be mutually exclusive. The theory posits that the team member will rely on the most salient goals when choosing how much effort to expend at a given moment. The theory notes, as an instance of goal congruence, that participants will only elect to expend effort if they believe that there is some probability the goal is attainable (Locke, Lee, \& Bobko, 1984).

Team Theory also notes that distractions may interfere with productivity, and that individual differences in ability may also affect productivity.
(Paulus \& Dzindolet, 1993). Indeed, the effects of anonymity (Connolly, Jessup, \& Valacich, 1990) may be explained as countervailing goal congruence effects: anonymity may reduce evaluation apprehension while increasing social loafing (Shepherd, Briggs, Reinig, Yen, \& Nunamaker, 1995-96). The effects of group size may be explained by countervailing effects of communication (more airtime fragmentation, but easier access to participants), deliberation (more distraction), information access (easier access to information held by others, but more information to wade through), and goal congruence (more evaluation apprehension, but more chance to get interests accommodated). Infinite variations in these four constructs may result in infinite variation in the quantity of ideas produced.

Team Theory also offers plausible explanations for variation in the quality of ideas produced. Team members with poor goal congruence may not make the effort required to generate good ideas. Indeed, if goal congruence were low enough the team 
might intentionally generate bad ideas. Difficulties with communication, or information access could consume enough cognitive resources to constrain deliberation, or poor deliberative processes could lead to poor ideas.

Indeed, much has been written about causes of quantity and quality in idea generation, but what of the connection between those two? Little has been written about that topic. The following paragraphs offer a causal model of that relationship derived from Team Theory.

Any demand on cognitive resources that resulted in lower idea quantity would, of necessity, also interfere with the thinking required for quality, so one might expect quality and quantity to covary. However, there may also be a more direct causal connection. Three mechanisms relating to the by airplane, a good quality solution that might have been overlooked without the balloon suggestion.

Secondly, as team members deliberate about ideas received from others, they may mentally counter-argue the ideas to test their merit (Chaiken, Liberman, \& Eagly, 1989; Petty \& Caciappo, 1986). Under such conditions even bad ideas would be useful. In counter-arguing a bad idea the participant may come to a more clear and complete understanding of the problem, which, in turn, should make them better able to produce high-quality solutions.

Finally, the communication of ideas among group members consumes attention resources, but it may be that receiving ideas from others produces less cognitive interference than generating them (Brainerd \& Reina, 1990). Thus, in the presence of many

Figure 3.

Nineteen Interrelated symptoms in the School of Business Task

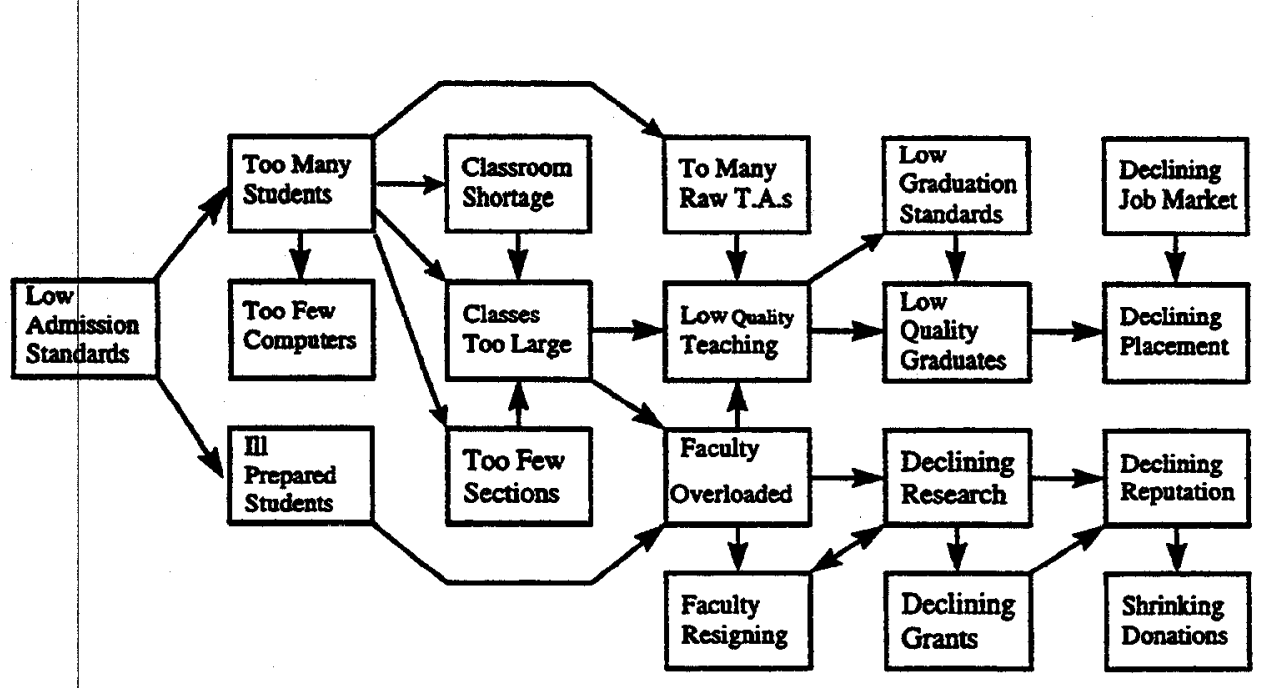

deliberation process suggest themselves (Figure 2). Firstly, as Osborn (1953) posited, team members in a brainstorming activity may derive inspiration from the ideas of others. It may be that the more ideas a group produces, the more chance there is that one person will trigger unexpected associations in the minds of other members as they deliberate. This could lead to a reframing or expanding of the solution space. Reframing the solution space might, in turn, lead the group to good quality ideas that might have otherwise been overlooked. For example, in 1909 someone might have suggested improving the mail service by sending letters across the sea with balloons. The balloon idea would be impractical, but the suggestion reframes the solution space from surface mail to surface and air mail. This, in turn, could allow someone else to suggest sending mail ideas generated by others, a team member may have more resources available to refine existing ideas, resulting in better overall idea quality.

To summarize, then, in the presence of many ideas, a team member may receive more inspiration, may counter-argue, and may refine existing ideas, leading to a better understanding of the problem and solution spaces, all of which in turn may result in the production of better quality ideas. Other things being equal, it may therefore be that an increase in idea quantity will cause an increase of idea quality.

From these theoretical arguments we derive the hypothesis:

HI: Groups producing more ideas will also produce higherquality ideas. 


\section{Methods}

\section{Participants}

The participants in this study were 290 undergraduate business students. Participants were randomly assigned to 58 groups of five students each.

\section{Task}

The participants engaged in a moderate-ambiguity variation on the School of Business task ${ }^{2}$ (Reinig, Briggs, Shepherd, Yen, \& Nunamaker, 1995-96; Wheeler \& Mennecke, 1992), subjects used electronic brainstorming to propose solutions for wicked problems in an imaginary school of business. We assigned each subject to one of five roles: Associate Dean, President of the Student Council, President of the Alumni Association, Chairperson of the Faculty Council, and Vice President of Undergraduate Instruction. Each was given a packet containing information about the assigned role. Each role had different information and a different interest in the outcome. The information cues required to infer the root causes of the symptoms were spread across the five roles. Participants could only infer the causes of the symptoms by sharing information.

The School of Business task is sufficiently complex to provide a level of challenge comparable to some real-world problem solving tasks. In the School of Business task, the group faced a total of 19 inter-related symptoms such as declining budgets, over-crowded classrooms, declining reputation, and faculty resignations because of overwork (Figure 3 ).

Solutions to many symptoms tended to exacerbate other symptoms, and symptom-based solutions that favored one role tended to be unfavorable to another.

It is interesting to note that the subjects found the task very realistic. Despite oral and written disclaimers that the scenario was imaginary, during debriefing many subjects asked when their recommendations would be forwarded to the administration of their university.

\section{Procedure}

All instructions given by experimenters to the participants were scripted Experimenters memorized their scripts, but carried them in their hands as back-up.

Participants signed an attendance sheet when they arrived at the study site, and then seated themselves before one of five computers. The computers were side-by-side facing the projection screen at the front of the room. One of three facilitators greeted the participants and read them instructions from a script. Participants received a packet of information and

\footnotetext{
${ }^{2}$ Several versions of the School of Business Task and other experimental tasks are available on the ISWORLD Web Site.
}

were given 10 minutes to read about their roles. None took longer than six minutes.

We wanted to assure that all the problems in the scenario surfaced before the group began to generate solutions. Therefore the facilitator conducted a structured interview with each subject in the presence of the others asking what problems the subject had identified in their role in the School of Business. An accomplice sat at another computer pretending to type the problems as the subjects identified them. At the end of the interviews the accomplice printed and distributed a standard set of problems, so all groups started generating solutions with an identical problem statement.

Participants were then instructed on using the electronic brainstorming tool. They were encouraged to think about all the problems posed by the group rather than just those contained in their own role. Participants were encouraged to generated as many different ideas as they could in the time available to them. They were instructed to enter wild and silly ideas as well as mainstream ideas in an effort to inspire one another to think beyond the obvious.

They were given 40 minutes to generate solutions. Experience in the field has shown that real groups working on real problems using electronic brainstorming tend to run out of ideas in about that much time. When the brainstorming time was elapsed, the participants were debriefed and released.

\section{Measuring Idea Quality}

Under Team Theory there can be no universal measures of productivity. Because productivity is defined as the degree to which the team achieves its goal, any measures of productivity will be goal-specific. In this task the goal was to generate solutions to the problems in the imaginary school of business. The quality an individual idea could therefore be judged in terms of the degree to which it would relieve the symptoms at the school of business.

There are two challenges associated with measuring idea quality. First one must devise a reliable way to measure the quality of individual ideas. Then one must decide how to aggregate the quality of individual ideas to rate the session. For all its symptomatic complexity, the version of the School of Business task used in this study had only two major causes: admission standards were too low, and too many students had been admitted to the university. Almost all other symptoms sprang from those causes. It was therefore relatively easy to evaluate solution quality based on whether they solved these two root problems. A solution that addressed all 19 symptoms could be considered superior to a solution that treated only one or two symptoms.

As a first step in this process we developed a box-and-arrow causal map of the problems represented in the scenario (Figure 
3). The next step involyed identifying all the unique ideas produced by each group. When extracting a list of unique solutions from a brainstorming session one can either aggregate or disaggregate solutions. For example, if a participants suggests:

"advertise in newspapers and on television,"

one may choose to aggregate that into simply:

"advertise in various media,"

or one may choose to disaggregate into:

"advertise in newspapers"

"advertise on television."

In the first effort to extract unique solutions, three independent coders tried to use an aggregation approach to extract solutions from four transcripts. Their idea lists only overlapped by about $67 \%$. In the next effort they used a disaggregation rule that stated "any unique verb-object pair intended to suggest an action for improving the symptoms constitutes a unique idea." Using this approach independently, the raters achieved more than 97\% overlap in their idea lists. The coders then divided the remaining 54 transcripts among them, and each transcript was extracted by only one coder.

Having extracted the unique ideas from 58 transcripts, the next task was to evaluate the quality of each individual solution. Three independent raters were briefed on the causal map of the problem space. Raters were then trained in a quality evaluation technique derived from the Holistic Grading Method, commonly used to evaluate the quality of written essays (Brandt 1995). Each idea in each transcript was rated separately by each of two coders using a four-point scale based on the following rubric:

A solution receives a score of 4 if it is easily implemented and if it solves both major problems completely.

A solution scores 3 if it is easily implementable, and would ease most symptoms considerably, but would not completely eliminate them. $O R$ it receives a score of 3 if it would be difficult to implement, but would completely solve both the major problems.

A solution scores $a 2$ if it would be very difficult to implement and would ease many symptoms considerably but would not completely eliminate them. $O R$ it receives a score of 2 if it is easily done, but would only have minor, marginal improvement on the symptoms.

A solution scores 1 if it can not be done or has no impact on the symptoms.

Coders were instructed to consider economic, technical, and political feasibility as a part of their evaluations. The independent raters then compared their ratings. If the rating on any idea was different by more than one point, a third coder settled the difference. The final quality score for a given solution was the sum of the two independent raters' scores.
Thus the possible score for a given idea ranged from 2 to 8 points. For the final analysis the scores were shifted downward two points so ideas with no value scored 0 , while ideas of highest value scored 6 . Three coders evaluated four transcripts and found they were in agreement (no more than one point different) on more than $99 \%$ of their evaluations. Two coders rated each of the remaining 58 transcripts.

The holistic evaluation method is a reliable way to rank order individual ideas, but it would not be useful for deciding how much better one idea is than another; the data produced by the method are ordinal, rather than ratio. Therefore care must be taken not to give too much credence in the magnitude of differences. Do four bad ideas really offer the same value as one good idea? Can one assert that an idea is 10 times better or 1000 times better than another? With that caveat in mind, let us consider how we might evaluate the quality of a whole brainstorming session.

There are two questions one can ask about the quality of brainstorming sessions:

1. Was the overall quality of one session higher than that of another?

2. Were there more good ideas in one session than in another?

The first question is problematic. What exactly is the overall quality of a brainstorming session? For some problems the emergence of one golden solution is sufficient to declare victory. For such a task the quality of the session would be defined in terms of the quality of the best ideas generated. Other problems can be addressed with a myriad of marginal gains. Even mediocre solutions may contribute a little toward the overall goal. In that case the quality of the session might be defined as the sum of the quality scores of all the useful ideas generated in the session.

The method of summing individual-idea-quality scores is also problematic because it treats the ordinal data of the holistic evaluation as if it were ratio data. Vastly different results might be produced, depending on how one decides to weight each level of the rubric.

Even if the quality data were ratio, a mean of individualidea-quality scores would not be a useful aggregate quality score. A treatment that increased the number of good ideas coming in might also increase the number of bad ideas coming in, resulting in no change of mean. A treatment might increase the number of bad ideas faster than it increases the number of good ideas. The number of good ideas would rise substantially, yet the mean would be lower. Thus, it would be impossible to interpret an average of all quality scores.

The second question - whether there are more good ideas in one session than another - is much more easily addressed. One may simply define a lower limit on the goodness of ideas, and then directly count the good ideas. This approach has the 
Table 2.

Correlations Between Quality and Quantity

\begin{tabular}{|c|c|c|c|}
\hline Quality Measure & Mean & STD & Correlation with Quantity \\
\hline \# of Ideas Scoring 0 & 27.72 & 18.14 & $.934 * \star$ \\
\hline \# of Ideas Scoring 1 & 9.70 & 5.58 & $.638 * *$ \\
\hline \# of Ideas Scoring 2 & 6.37 & 4.14 & $.464 * \star$ \\
\hline \# of Ideas Scoring 3 & 2.10 & 1.80 & $.397 \star \star$ \\
\hline \# of Ideas Scoring 4 & 1.41 & 1.35 & $.241 *$ \\
\hline \# of Ideas Scoring 5 & 1.36 & 1.20 & $.257 *$ \\
\hline \# of Ideas Scoring 6 & 1.94 & 1.03 & $.253^{\star}$ \\
\hline \# of Mediocre Ideas (score of 1,2 or 3 ) & 18.18 & 8.66 & $.717 * \star$ \\
\hline \# of Good Ideas (score of 4,5 , or 6 ) & 4.72 & 2.13 & $.421 * \star$ \\
\hline \# of Useful Ideas (score of 4 or 5 ) & 2.77 & 1.90 & $.335 * \star$ \\
\hline \# of Outstanding Ideas (score of 6 ) & 1.94 & 1.03 & $.253 \star$ \\
\hline Quantity & 50.63 & 24.06 & 1.0000 \\
\hline
\end{tabular}

advantage that it converts the ordinal data of the holistic evaluation to a ratio-data aggregate. Direct comparison of sums or means could be meaningfully interpreted.

The statistical analysis in this paper addresses the question, "When we get more ideas, do we get more good ideas or do we just get more trash?" It reports and analyzes the number of good, bad, or indifferent ideas produced in a session by examining correlations and linear regressions.

\section{Results}

Analysis of the 58 brainstorming transcripts revealed that all qualities of solution quality correlated significantly with the quantity of ideas generated (Table 2.). Idea quantity had a correlation of 0.93 the number of useless ideas (those that make little or no difference on any symptom, having a quality score of 0 ). The strength of correlation dropped as the quality of solutions increased. The correlation between quantity and the number of outstanding ideas (those that directly solve the root problems) was 0.25 .

Eliminating the useless ideas from consideration, we clustered the remaining ideas into two categories: Mediocre ideas that scored 1,2, or 3; and Good ideas that scored 4,5, or 6 . Both mediocre and good ideas correlated significantly with quantity. Further analysis of the good ideas divided them into useful ideas, scoring 4 or 5 , and outstanding ideas, which scored 6. Remember that in order to score a 6 , the ideas had to be feasible, and had to solve the major problems completely. Both the moderately good and the outstanding ideas correlated with quantity of ideas.

We examined the relationship between quality and quantity in more detail by conducting simple linear regressions of mediocre ideas and good ideas on quantity of ideas generated. The tests revealed a significant linear relationship in both cases (Table 1.). The slope of the least-squares line for good ideas was quite small. The groups had to generate about 25 ideas to get one good idea. The model explained about $18 \%$ of the

Table 1.

Simple Linear Regression of Idea Quality on Idea Quantity

\begin{tabular}{cccc}
\hline Quality Measure & Slope & Intercept & $\mathrm{R}^{2}$ \\
\hline \# of Mediocre Ideas & $.258^{\star \star}$ & $5.11^{\star \star}$ & .514 \\
\# of Good Ideas & $.037^{\star}$ & $2.82^{\star}$ & .177 \\
\hline \# of Useful Ideas & $.026^{\star}$ & $1.43^{\star}$ & .112 \\
\# of Outstanding Ideas & .010 & $1.3^{\star \star}$ & .064 \\
\hline$\star$ - Signif. LE .05 & $\star \star-$ Signif. LE.01 & (2-tailed)
\end{tabular}


variance in idea quality.

We analyzed the good ideas in more detail by conducting simple linear regressions of useful ideas and outstanding ideas. There was a significant linear component in the relationship between the number of useful ideas and the overall quantity of unique ideas generated. This model accounted for $11 \%$ of the variance. The regression line had a slope of 0.026 , which suggests that participants had to generate approximately 40 solutions to get one useful solution.

The analysis did not reveal a significant linear relationship between quantity of ideas and the number of outstanding ideas the groups generated.

\section{Discussion}

The data support the hypothesis; The teams that produced more ideas did tend to produce more good ideas, although this finding should not be taken at face value. The data also illustrate that this model is a woefully incomplete explanation for idea quality.

The higher the quality, the less it follows quantity. Quantity accounts for almost all the variance in the useless-idea category (ideas which would have little or no effect on symptoms). If the group produces more ideas, it will absolutely produce more bad ideas, in lock step. This is not necessarily a bad thing. Remember, Model the model above suggests that counterarguing bad ideas leads the participant to a better understanding of the problem space. On the other hand, bad ideas also impose something of a cognitive load, so their value is not and unmixed blessing. At some point the bad ideas may become distracting noise that stifles the ability of the group to deliberate and find the best ideas. Further research may provide insight into the break-even point at which the cost of bad ideas outweighs the value they provide for clarifying the problem and solution spaces.

When a group produces more ideas, they also produce a few more useful ideas, but the data suggest that factors other than quantity play a much more important role in determining how many useful ideas will be produced. By the time one considers the generation of outstanding ideas, the role of quantity in the outcome is minute. There is a significant correlation, but it is small enough to be of little substance.

\section{Implications for Researchers}

This study provided some empirical support for the causal model of brainstorming quality posited in Figure 2 . It may well be that received ideas cause some level of inspiration, counterarguing, and idea refinement that leads to the generation of more good ideas. The lower one is willing to set the bar, the stronger the association appears to be.

However, the model "Quality follows Quantity" is clearly incomplete, and as such is inadequate for predicting and explaining idea quality. Note that the regression model only explains $18 \%$ of the number of good ideas, only $11 \%$ of the number of useful ideas, and only $6 \%$ of the variance in the number of outstanding ideas. Some other factor or factors account for the lion's share of the good ideas produced. Further theoretical and empirical research will be required to develop a more robust explanation for idea quality.

As discussed above, Team Theory offers a number of possible explanations, ability, goal congruence, and factors relating to the deliberation process being chief among them. (Figure 4.).

The results of this study also suggest that, alas, brainstorming researchers must take up again their heavy yoke, to continue the laborious and expensive task of measuring idea quality. The correlation between quantity and quality is probably too tenuous for us to presume that a treatment which increases quantity will

Figure 4.

An Extended Causal of the Number of Good Ideas produced in a Brainstorming Session

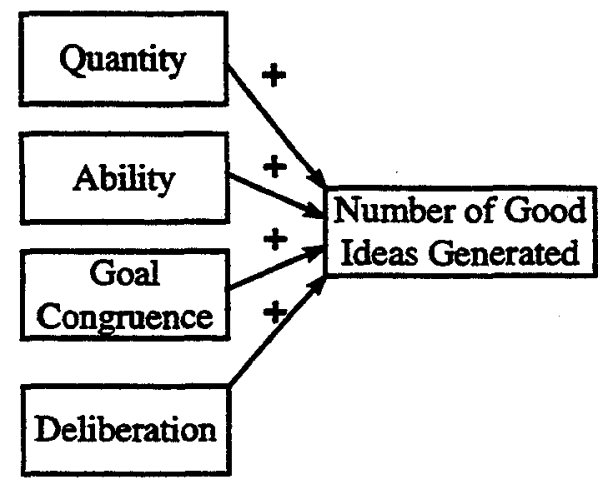

by definition also increase quality. Other factors not accounted for by the quality-quantity model may well counter and outweigh that effect. It is conceivable that a treatment could make a group massively efficient at creating ineffective ideas.

Because idea quality is an upper limit on group performance, we must guard against unintended quality effects as we devise new ways to support idea generation. However, the holistic evaluation technique described above offers a reliable and low-cognitive-load method for conducting those analyses, which should ease the burden slightly.

As with every study, this one is limited in several ways. First, because it follows the investigative rather than the experimental paradigm, its design does not allow us to directly infer causality. As such, its findings are suggestive, rather than conclusive. Further research will be required to clearly test the causal links in the quality model. 
Next, all the participants were undergraduates, all participated in five-person groups, and all worked on the same task. Further research will be required to test whether the relationships observed here hold for other populations, other group sizes, and for other tasks. Although the participants found the task engaging and realistic, they did not have a large personal stake in the outcome. It will be necessary to investigate the degree to which vested interests affect the relationships we observed.

\section{Implications for Practitioners}

Low quality follows quantity. Moderate quality follows quantity, too, but not as closely. Higher quality does not seem to depend much on quantity. In the task reported here, the people who produced the fewest unique ideas produced about the same number of outstanding ideas as the people who produced the most unique ideas. This may be a bias built into the task. There were only so many solutions that could help, and all the groups found most of those few solutions. However, it may be that if the team seeks a single golden solution, they would be better of to relax and reflect as they work. On the other hand, if a problem has no golden solution, as many real world problems do not, then it might be worth driving the group to produce a great many ideas, to maximize the availability of modestly useful solutions.

\section{Conclusions}

This paper examined the question, "Does Quality Follow Quantity in Electronic Brainstorming." The answer seems to be yes, but the better the ideas you need, the less help you get from raw quantity. Further research is required to tease out other important determinants of idea quality and to develop more effective and less expensive ways to study the phenomenon.

\section{References}

Ajzen, I. From intentions to actions: A theory of planned behavior. In Kuhl, J. \& Beckman, J. (Eds.), Action Control: From cognition to behavior, Berlin: SpringerVerlag, 1985, 11-39.

Andriole, S. J. Handbook of Problem Solving an analytical methodology, Petrocelli Books, Inc. New York, 1983.

Brainerd, C.J., \& Reina, V.F. Gist is the Grist: Fuzzy Trace Theory and the New Institutionalism. Developmental Review, 10(3), 3-47.

Brandt, S. Using GSS to improve Post Secondary Education. Doctoral Dissertation, University of Arizona 1996.

Briggs, R.O. The Focus Theory of Group Productivity and its application to development and testing of electronic group support systems. Doctoral Dissertation, University of Arizona, 1994.
Briggs, R.O., \& Nunamaker, J.F. The Focus Theory of Group Productivity. CMI Working Paper Series, CMI 96-1, University of Arizona MIS Department, 1996.

Brightman, H. J. Problem Solving: A Logical and Creative Approach, Business Publishing Division, College of Business Administration, Georgia State University, Atlanta, 1980.

Bross, Irwin D. F. Design for Decision, The Macmillan Company, New York, 1953.

Burgoon, J. K Nonverbal signals. In M. L. Knapp and G. R. Miller (Eds.) Handbook of Interpersonal Communications. London: Sage. 1985.

Campbell, J.P., \& Prichard, R.D. "Motivation theory in industrial and organizational psychology. Dunnete, M.D. (Ed.), Handbook of Industrial and Organizational Psychology. Chicago: Rand-McNally, 63-130.

Chaiken, S., Liberman, A., \& Eagly, A.H. Heuristic and systematic processing within and beyond the persuasion context. In J.S. Uleman \& J.A. Bargh (Ed.) Unintended Thought. New York: Guilford Press, 1989.

Connolly, T., Jessup, L.M., \& Valacich, J.S. Effects of anonymity and evaluative tone on idea generation in computer-mediated groups. Management Science, 36, 6, 1990, 689-703.

Daft, R. L., and Lengel, R. H. A proposed integration among information requirements, media richness, and structural design. Management Science, 32, 1986, 191-233.

Daft, R. L., and Weick, K. E. Toward a model of organizations as interpretive systems. Academy of Management Review, 9, 1984, 284-295.

Dennis, A.R., \& Gallupe, R.B. A History of GSS empirical research: Lessons Learned and Future Directions, in L Jessup \& J. Valacich (Eds.), Group Support Systems: New Perspectives, New York: Macmillan, 1993.

Dennis, A.R., Nunamaker, J.F., \& Vogel, D.R. A comparison of laboratory and field research in the study of electronic meeting systems. Journal of Management Information. Systems, 7(3), 1991, 107-135.

Dennis, A.R., Valacich, J.S., \& Nunamaker, J.F., AI experimental investigation of small, medium and largi groups in an electronic meeting system environmen IEEE Transaction Systems, Man Cybernetics, 20(5) 1990, 1049-1057.

DeSanctis, G., \& Gallupe, R. B. A Foundation for the study o group decision support systems. Management Science 33(22), 1987, 589-609.

Diehl, M., and Stroebe, W. Productivity Los in Brainstormin Groups: Toward the solution of a riddle. J. Personalit and Social Psychology, 53(3), 1987, 497-509. 
Dunker, K. On Problem Solving, Psychological Monographs, 58(5), 1945, 47-90.

Fjermestad, J., Hiltz, S. R., \& Turoff, M. An integrated framework for the study of group decision support systems. Proceedings of the Twenty-Sixth Annual Hawaii International Conference on Systems Science, IV, 1993, 179-188

Gallupe, R.B., Dennis, A.R., Cooper, W.H., Valacich, J.S, Bastianutti, L.M, \& Nunamaker Jr., J.F. Electronic brainstorming and group size. Academy of Management Journal, 35(2), 1992, 350-369.

Gilbert, D.T. \& Osbome, R.E. Thinking backward: Some curable and incurable consequences of cognitive business. Journal of personality and social psychology, 57(6), 1989, 940-949.

Gopal, A., Bostrom, R, Chin, W. Applying Adaptive Structuration Theory to Investigate the Process of Group Support Systems Use. Joumal of Management Information Systems, 9(3), 1993, 45-69.

Hatch, R.A. Communication in Business. Chicago: Science Research Associates, 1977.

Kosslyn, S.M. The medium and the message in mental imagery. Psychological Review, 88, 1981, 46-66.

Kuhl, J. Volitional mediators of cognition-behavior consistency: Self-regulatory processes and action versus state orientation. In J. Kuhl \& J. Beckmann (Eds.), Action Controls: From Cognition To Behavior. Berlin: Springer-Verlag, 101-128.

Locke, E.A., Fredrick, E., Lee, C., \& Bobko, P. Effect of self efficacy, goals, and task stragedies on task performance. Joumal of Applied Psychology, 69(2), 241-251.

McGrath, J.E. Time, interaction, and performance (TIP): A theory of groups. Small Group Research, 22(2), 1991, 147-174.

Osborn, A.F. Applied Imagination: Principles and procedures of creative thinking, New York: Scribner's, 1953.

Paulus, P.B. \& Dzindolet, M.T. Social Influence Processes in Group Brainstorming. Joumal of Personality and Social Psychology, 64(4), 1993, 575-586.

Petty, R. E., \& Caciappo, J. T. The Elaboration Likelihood Model of Persuasion. In L. Berkowitz (Ed.), Advances in experimental social psychology, 19, New York: Academic Press, 1986, 123-205.

Poole, M.S., \& Jackson, M.H. Communication Theory and Group Support Systems. in Jessup, L.M \& Valacich, J.S (Eds.) Group Support Systems: New Perspectives. New York, NY: Macmillan Publishing Company, 1993, 281-293.

Prichard, R.D., Jones, S.D., \& Roth, P.L. The effects of feedback, goal serting, and incentives on organizational productivity. Joumal of Applied Psychology Monograph Series, 73(2), 1990, 337-358.
Reinig, B., Briggs, R.O., Shepherd, M., Yen, J., \& Nunamaker, J. Beyond Productivity: Affective Reward and GSS Journal of Management Information Systems, 12(3),

Shannon, C.E., \& Weaver, W. The Mathematical Theory of Communication. Urbana, Illinois: University of Illinois Press, 1964.

Shepherd, M.M., Briggs, R.O., Reinig, B.A., Yen, J., \& Nunamaker Jr., J.F. Invoking social comparison to improve electronic brainstorming: Beyond Anonymity. Journal of Management Information Systems, 12(3) 1995-96, 155-170.

Tubbs, M.E. \& Ekeberg, S.E. The role of intentions in work motivation: Implications for goal-setting theory and research. Academy of Management Review, 16(1), 1991, 180-199.

Valacich, J.S., Wachter, R., Mennecke, B.E., \& Wheeler, B.C. (1993) Computer-Mediated Idea Generation: The Effects of Group Size and Group Heterogeneity. The Proceedings of the Twenty-sixth International Conference on Systems Sciences, IV, 1992, 152-160. 